\title{
SISTEM INFORMASI BIMBINGAN ONLINE PRODI TEKNIK ELEKTRONIKA POLITEKNIK HARAPAN BERSAMA BERBABIS WEB
}

\author{
Ulil Albab $^{1}$, Rony Darpono ${ }^{2}$, Qirom ${ }^{3}$ \\ Teknik Elektronika Politeknik Harapan Bersama Tegal \\ email: ${ }^{1}$ italbabz@gmail.com, ${ }^{2}$ ronydr80@ gmail.com, ${ }^{3}$ qirom.bahagia2@ gmail.com
}

\begin{abstract}
Program Studi Diploma III Teknik Elektronika merupakan salah satu Program Studi di Politeknik Harapan Bersama. Salah satu kegiatan akademik di Prodi Teknik Elektronika di akhir semester VI yaitu Praktek Kerja Lapangan (PKL) dan Tugas Akhir (TA). Saat ini kegiatan bimbingan antara Dosen dan Mahasiswa dilakukan dengan bertatap muka, hal ini menjadikan sulitnya interaksi antara keduanya. Dengan memanfaatkan teknologi informasi diharapkan dapat mempermudah proses bimbingan secara online melalui media website serta manajemen waktu tertata dengan baik.

Framework YII merupakan Framework PHP untuk membuat website dinamis dengan MySQL sebagai media penyimpanan data. YII menggunakan konsep Model View Controller (MVC) yang berarti hubungan database, layout, permintaan pengguna sudah terstruktur. Dengan banyaknya pengguna maka dibutuhkan Role Base Access Control (RBAC) YII sebagai pengelola batasan hak akses pada setiap halaman.
\end{abstract}

Kata Kunci - Bimbingan PKL/TA, Teknologi Informasi, Website, MySQL, PHP, YII

\section{PENDAHULUAN}

Program Studi Diploma III Teknik Elektronika merupakan salah satu Program Studi di Politeknik Harapan Bersama berdiri tahun 2002 sesuai dengan Keputusan Mentri Pendidikan Nasional Republik Indonesia Nomor 128D/O/2002 yang memfokuskan diri pada kemajuan dan perkembangan Teknologi dibidang Instrumentasi, Elektonika, Listrik, Komputer dan Jaringan serta telah Terakreditasi oleh Badan Akreditasi Nasional - Perguruan tinggi (BAN-PT) sesuai surat keputusan nomor 014/SK/BAN-PT/AK-XII/DplIII/I/2013. Program Studi Teknik Elektronika saat ini terus memperbaiki dalam hal manajemen, fasilitas dan tenaga pengajar demi meningkatkan mutu pendidikan. Dengan perbaikan yang ada diharapakan kompetensi lulusan dapat tercapai dengan baik sesuai visi dan misi.

Semakin berkembangnya era digitalisasi salah satunya adalah media webiste yang menunjang dalam hal kegiatan atau aktivitas untuk mendapatkan informasi. Teknologi informasi dapat dipergunakan untuk menggantikan peran manusia. Dalam hal ini, teknologi informasi melakukan otomasi terhadap suatu tugas atau proses. Teknologi informasi juga dapat memperkuat peran manusia, yakni dengan menyajikan informasi terhadap suatu tugas atau proses. Selain itu, teknologi informasi pun berperan dalam restrukturisasi terhadap peran manusia. Dalam hal ini, teknologi berperan dalam melakukan perubahan-perubahan terhadap sekumpulan tugas atau proses. Peran teknologi informasi dalam perkembangannya dapat mengubah paradigma lama yang telah semakin sulit untuk menyesuaikan diri pada perkembangan kebutuhan manusia yang semakin kompleks, bahkan merombak total aturan-aturan baku yang telah lama berlangsung. Dalam hal ini teknologi informasi lebih bersifat sebagai katalisator perubahan tersebut.

Kendala yang dihadapi saat ini adalah sulitnya manajemen waktu dan interaksi antara Dosen dan Mahasiswa terkait proses bimbingan Praktek Kerja Lapangan (PKL) maupun Tugas Akhir (TA). Dengan memanfaatkan peran teknologi informasi proses manajemen dan data dapat tertata dengan baik. Hal ini memudahkan dan menghemat waktu baik Dosen dan Mahasiswa dari segi interaksi untuk bimbingan secara online.

YII Framework merupakan salah satu framework PHP yang tersedia sebagai kerangka kerja dalam pembuatan website bersifat opensource. YII dibuat menggunakan konsep Model View Controller (MVC) yang berarti Model berhubungan dengan Database, View layout dan Controller setiap permintaan user. YII menyediakan berbagai fitur dan bersifat professional untuk membuat maupun mengembangkan projek yang kuat dalam skala besar.

\section{PENELITIAN YANG TERKAIT}

\subsection{Tinjau Pustaka}

Pada tinjauan pustaka ini membahas penelitian sebelumnya terkait tentang Bimbingan Online sebagai berikut:

1. Frederick Constantianus, Analisa dan Desain Sistem Bimbingan Tugas Akhir Berbasis Webdengan Studi Kasus Fakultas Teknologi Informasi Universitas Kristen Maranatha Bandung, Penulis ini membahas penerapan sistem ini maka proses pencatatan data konsultasi dapat lebih akurat dibanding metode konvensional, dan juga dosen pembimbing dapat mengetahui data terakhir konsultasi seorang mahasiswa bimbingannya.

2. Henry Kurniawan, Tri Sandika, Desain dan Implementasi E-Bimbingan di Politeknik Negeri Lampung, Penulis ini membahas merancang sebuah sistem "E-Bimbingan" di Politeknik Negeri Lampung yang mampu memfasilitasi proses bimbingan secara lebih baik.

\section{METODE PENELITIAN}

1. Menentukan tempat dan obyek penelitian untuk diterapkan sistem informasi bimbingan online.

2. Mengumpulkan data dan informasi yang dibutuhkan dalam perancangan database.

3. Menggunakan Framewor YII dalam pembuatan website.

4. Membuat user interface dengan mengambil tema dari obyek penelitian.

5. Menentukan level akses dengan menggunakan Role Base Access Control (RBAC) berdasarkan level dari setiap pengguna.

6. Evaluasi kekurangan sistem dan kebutuhan data yang diperlukan.

\section{HASIL DAN PEMBAHASAN}

\subsection{Hasil Penelitian}

Hasil penelitian yang didapat selama proses penelitian yaitu mengimplementasikan sistem yang sudah dibuat dengan melakukan tahap pengujian atau uji coba berdasarkan hasil perancangan serta menerapkan komponen pendukung dan 
tergorganisir dengan baik yang menerapkan konsep Model View Controller (MVC).

sudah diimplementasikan :

1. Halaman Login

Halaman login yaitu sebagai halaman awal untuk pengguna login ke halaman utama dengan memasukan username dan password. Pada halaman login akan dilakukan pengecekan berdasarkan hak akses pengguna menggunakan Role Base Access Control (RBAC) seperti Routes, Permission, Role, Rule dan Assigment.

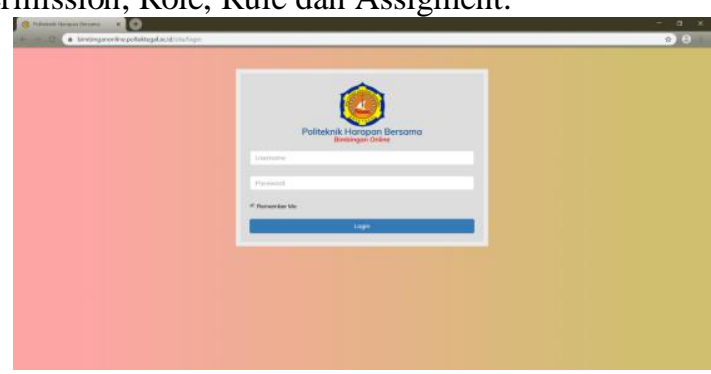

Gambar 1 Halaman Login

2. Halaman Utama

Halaman utama merupakan halaman apabila pengguna berhasil login dengan benar. Pilihan menu yang tersedia menyesuaikan hak akses masing-masing pengguna.

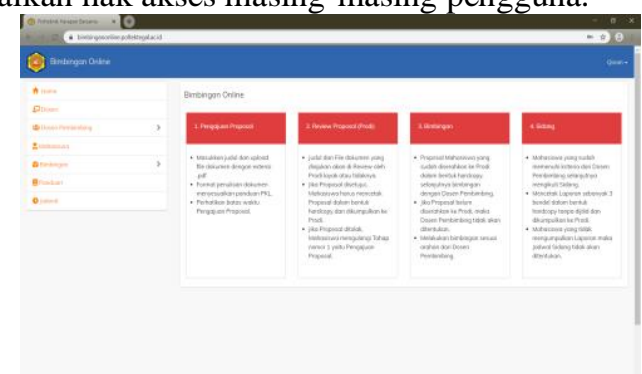

Gambar 2 Halaman Ketua Program Studi

\subsection{Pembahasan}

Tahapan yang dilakukan berdasarkan metode penelitian sehingga menghasilkan berupa aplikasi website menggunakan Framework YII diantaranya sebagai berikut:

1. User Interface

Pembuatan User Interface memanfaatkan bootstrap sebagai Framework CSS dengan penggunaan seperti Navigation Bar, Side Bar dan pengaturan tata layout. Dalam penerapannya boostrap di custom sedemikian rupa sehingga kebutuhan User Interface sesuai dengan tema pembuatan. Booostrap mendukung versi desktop dan mobile yang berarti saat mengakses website menggunakan device berbeda, ukuran dari layout akan menyesuaiakan.

2. Database

Penerapan database menggunakan MySQL dengan enginne InnoDB sebagai media penyimpanan. InnoDB menyediakan fitur transactions serta foreign key. Hal ini memudahkan untuk menghubungan atau merelasikan antar table yang berbeda. Tujuan dari penggunaan InnoDB agar data lebih terorganisir dengan baik serta pengambilan data pada table yang berelasi.

3. Program

Penulisan program menggunakan Framework YII dengan text editor PHP Designer. Framework YII bersifat berorientasi objek yang merupakan paradigma dengan penerapan konsep objek meliputi class, method dan attribute. Pembuatan website menggunakan YII dapat
4. Evaluasi mengevaluasi kinerja dari aplikasi website dengan menambahkan kebutuhan data, kekurangan sistem, memperbaiki bug dan kecepatan akses.

\section{KESIMPULAN}

1. Dengan kegiatan penelitian di Program Studi Teknik Elektronika Politeknik Harapan Bersama memberikan pemahaman memanfaatkan media website dalam proses bimbingan PKL atau Tugas Akhir secara online.

2. Mempermudah interaksi antara Dosen Pembimbing dan Mahasiswa tanpa harus bertatap muka.

3. Mempermudah administrasi Program Studi mengelola proses bimbingan dari tahap Proposal sampai Seminar atau Sidang.

\section{DAFTAR PUSTAKA}

[1] Doyle, Matt. Beginning PHP 5.3. Wiley Publishing, Inc. Indianapolis.

[2] Dr. H. A. Rusdiana, M.M. Moch. Irfan, S.T., M. Kom. 2014. Sistem Infromasi Manajemen. Pustaka Setia. Bandung.

[3] Jason, W Gilmore. 2010. Beginning PHP and MySQL from Novice to Professional. Apress. New York.

[4] K Yasin. Apa Itu Web Server dan Fungsinya?. https://www.niagahoster.co.id/blog/web-server-adalah/. Diakses pada 13 Agustus 201920.00 WIB.

[5] Rohndatul Mutaalimah, Imam Rosyadi. 2015. Sistem Informasi Bimbingan Tugas Akhir Online pada Politeknik Muhammadiyah Pekalongan. SURYA INFORMATIKA.

[6] Xue Qiang, Makarov Alexander, Brandt Carsten, Paul Klimov dan YII Community. 2014. The Definitive Guide to YII 2.0.
Setelah aplikasi digunakan tahap selanjutnya adalah 